\title{
DECARBOXYLATIVE C-C BOND CLEAVAGE REACTIONS VIA OXAPALLADACYCLES
}

\section{Masanari Kimura,* Tomohiko Kohno, Kei Toyoda, and Takamichi Mori}

Graduate School of Science and Technology, Nagasaki University, 1-14 Bunkyo-machi, Nagasaki, 852-8521, Japan. E-mail; masanari@nagasaki-u.ac.jp

Dedicated to Prof. Dr. Albert Eschenmoser's on the occasion of his $85^{\text {th }}$ birthday.

\begin{abstract}
In the presence of $\operatorname{Pd}(0)$ catalyst and triethylborane, 3-hydroxy-4-pentenoic acids undergo $\mathrm{C}$-C bond cleavage reactions via oxapalladacyclopentanones to provide conjugated dienes with evolution of carbon dioxide.
\end{abstract}

Metallacycles are attractive key intermediates for constructing important fundamental constituents of complex molecules and fine chemicals. ${ }^{1}$ Oxidative cyclizations of conjugated dienes and carbonyl compounds with transition metals are efficient strategies for highly regio- and stereocontrolled C-C bond formation via oxametallacycles. ${ }^{2}$ Although the C-C bond cleavage reaction involving metallacycles has received less attention in comparison to $\mathrm{C}-\mathrm{C}$ bond formation, it is equally capable of significant synthetic utility for efficient chemical transformations. ${ }^{3}$

We have previously developed a smooth transformation of vinyl cyclic carbonates into the corresponding $\omega$-dienyl aldehydes by decarboxylative fragmentation through a key oxapalladacyclopentane intermediate, triggered by oxidative addition of a $\mathrm{Pd}(0)$ catalyst to the allylic C-O bond (Scheme 1). ${ }^{4}$ Furthermore, 4-pentene-1,3-diols of a wide structural variety, which can be prepared in a straightforward manner from mono- or bicyclic ketones with $\alpha, \beta$-unsaturated aldehydes, also underwent the dehydrative $\beta$-carbon elimination of oxapalladacycles promoted by $\mathrm{Ph}_{3} \mathrm{~B}$ and $\mathrm{Pd}(0)$ catalyst. ${ }^{5}$ This procedure is superior to the cyclic carbonate method, not simply because we can save one step (carbonation), but because we can utilize a wide variety of stereoisomers of diols that cannot form carbonates as single isomers due to steric reasons. 


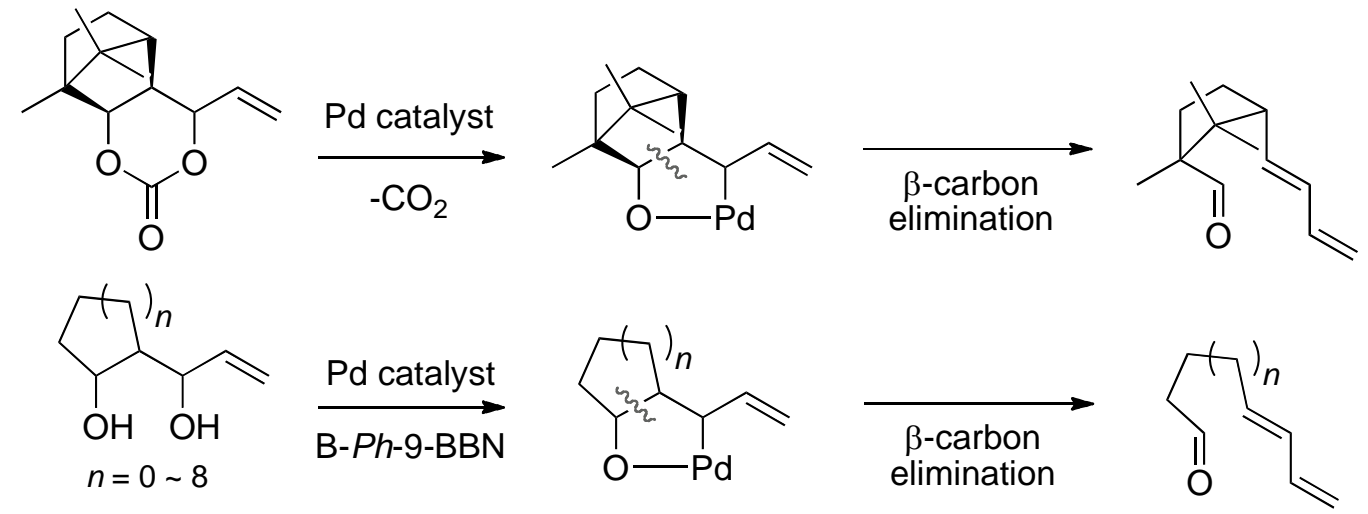

Scheme 1. Pd-Catalyzed $\beta$-Carbon Elimination via Oxapalladacycle

Herein, we report that $\mathrm{Et}_{3} \mathrm{~B}$ nicely activates 3-hydroxy-4-pentenoic acids which are prepared from esters or lactones with $\alpha, \beta$-unsaturated aldehydes to undergo the decarboxylative $\beta$-carbon elimination via an oxapalladacyclopentane to afford a conjugated diene (Scheme 2). While it has been reported that 3-acetoxy-4-pentenoic acid underwent a similar decarboxylative C-C bond cleavage reaction promoted by Pd catalyst in the presence of triethylamine, ${ }^{6}$ the present study is more convenient for the stereodefined construction of conjugated dienes from readily available starting materials as mixtures of diastereomeric isomers. ${ }^{7}$ Furthermore, the Pd-catalyst/ $\mathrm{Et}_{3} \mathrm{~B}$ system is also superior for the direct generation of $\pi$-allylpalladium species from allyl alcohols.

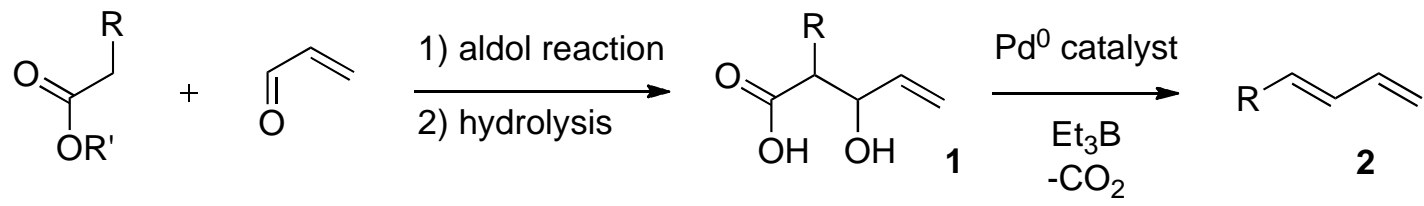

Scheme 2. Efficient Synthesis of Conjugated Diene via Decarboxylative C-C Bond Cleavage Reaction of 3-Hydroxy-4-pentenoic Acid Prepared from Acrolein and Esters

The reaction was undertaken with great ease just by exposing the 3-hydroxy-4-pentenoic acids to a mixture of $\mathrm{Pd}\left(\mathrm{PPh}_{3}\right)_{4}$ catalyst and $\mathrm{Et}_{3} \mathrm{~B}$ in THF under nitrogen atmosphere. Among these investigations with excess amount of $\mathrm{Et}_{3} \mathrm{~B}$, the reaction required 3.6 equivalents of $\mathrm{Et}_{3} \mathrm{~B}$ at $67{ }^{\circ} \mathrm{C}$ to consume the substrate completely. ${ }^{8}$ Table 1 summarizes the results obtained for a wide structural variety of 3-hydroxy-4-pentenoic acids under optimized conditions. ${ }^{9}$ 
<smiles>[R]C=CC(O)C([R1])C(=O)O</smiles><smiles>[R]C=CC=C[R]</smiles>

Table 1. Pd-Et $t_{3} B$ Promoted Decarboxylative C-C Bond Cleavage Reaction ${ }^{a}$

\begin{tabular}{|c|c|c|}
\hline run & $\begin{array}{l}\text { substrate } \\
\text { [ratio] }\end{array}$ & $\begin{array}{c}\text { product } \\
\% \text { isolated yield }[E: Z]\end{array}$ \\
\hline
\end{tabular}

1<smiles>O=C(O)C(Cc1ccccc1)C(O)C=Cc1ccccc1</smiles>

[3:1]

2<smiles>CC=CC(O)C(Cc1ccccc1)C(=O)O</smiles>

3<smiles>C=C(C)C(O)C(Cc1ccccc1)C(=O)O</smiles>

4<smiles>CC(C)=C(C)C(O)C(Cc1ccccc1)C(=O)O</smiles>

5<smiles>C=CC(O)C(Cc1ccccc1O)C(=O)O</smiles>

6<smiles>O=C(O)C(Cc1ccccc1O)C(O)C=Cc1ccccc1</smiles>

7<smiles>C=CC(O)C(C(=O)O)C1CCC2CCC21</smiles>

1<smiles>C(/C=C/c1ccccc1)=C\Cc1ccccc1</smiles>

2a: $95 \%$ [18:1]

1<smiles>CC=CC=CCc1ccccc1</smiles>

2b: $78 \%[5: 1: 1]^{b}$

18<smiles>C=C(C)C=CCc1ccccc1</smiles>

2c: $86 \%[E]$

72<smiles>CC=C(C)C=CCc1ccccc1</smiles>

2d: $65 \%[26: 7: 1]^{c}$

3<smiles>C=C/C=C/Cc1ccccc1O</smiles>

2e: $64 \%[3: 1]$
3<smiles>Oc1ccccc1C/C=C/C=C/c1ccccc1</smiles>

3<smiles>C=C/C=C/C1CCC(O)C1</smiles>

2g: $84 \%$ [11:1]

1<smiles>C=C/C=C/CCCCO</smiles>

2h: $99 \%$ [4:1]

1h $[2: 1]$

${ }^{a}$ Reaction conditions: substrate $(0.5 \mathrm{mmol}), \mathrm{Pd}\left(\mathrm{PPh}_{3}\right)_{4}(5 \mathrm{~mol} \%), \mathrm{Et}_{3} \mathrm{~B}$ (3.6 eq) in THF $(2.5 \mathrm{~mL})$ at $67 \mathrm{FC}$ under $\mathrm{N}_{2} .{ }^{b}$ Ratio of 1-phenyl-2,4-hexadiene. $(2 E, 4 E):(2 E, 4 Z):(2 Z, 4 E)=$ 5:1:1. ${ }^{c}$ Ratio of 4-methyl-1-phenyl-2,4-hexadiene. $(2 E, 4 E):(2 E, 4 Z):(2 Z, 4 E)=26: 7: 1$. 
A mixture of syn-1a and anti-1a in a 3:1 ratio, which was prepared from cinnamaldehyde and methyl 3-phenylpropionate, clearly undergoes $\beta$-decarboxylative $\mathrm{C}$-C bond cleavage to provide $(E, E)$-pentadiene 2a with high stereoselectivity in excellent yield (run 1). A methyl group substituted allylic alcohol $\mathbf{1 b}$ afforded (2E, 4E), (2E, 4Z), and (2Z, 4E)-1-phenyl-2,4-hexadiene $\mathbf{2 b}$ in a 5:1:1 ratio (run 2). $\beta$-Methallyl alcohol shows exclusive $E$-stereoselectivity to give $(E)$-2c as the sole product owing to the bulky steric repulsion between the benzyl group and the methyl substituent on the allylic moiety (run 3). $\beta, \gamma$-Dimethyl substituted allylic alcohol 1d displays moderate yield with three isomers of (2E, $4 E$ ), (2E, $4 Z$ ), and (2Z, 4E)-2d in a 26:7:1 ratio (run 4). 3-Hydroxy-4-pentenoic acids possessing o-hydroxyphenyl groups participate in similar C-C bond cleavage reactions in 48-64\% yields (runs 5 and 6). The lower yields stem from competing partial lactonization, which leads to the original dihydrocoumarin skeletons. ${ }^{10} \quad \beta$-Hydroxycarboxylic acids $\mathbf{1 g}$ and $\mathbf{1 h}$, which were prepared from 7-membered ring lactones with acrolein, provided the desired dienyl alcohols $\mathbf{2} \mathbf{g}$ and $\mathbf{2} \mathbf{h}$ in excellent to quantitative yields (runs 7 and 8).

The stereochemical outcome of the dienyl moiety may be rationalized according to the proposed reaction mechanism shown in Scheme 3. We postulate that syn-oxapalladacyclopentanone-I is generated by oxidative addition of the $\operatorname{Pd}(0)$ metal to the allylic position of anti-1 activated by $\mathrm{Et}_{3} \mathrm{~B}$ with inversion of configuration. The intermediate syn-I then isomerizes to the sterically more stable anti-I form by $\sigma-\pi-\sigma$ interconversion via the seven-membered ring palladacycle II. Thus, the $\pi$-allylpalladium intermediates syn-I and anti-I could both undergo the C3-C4 bond fission with evolution of carbon dioxde to provide (Z)-2 and (E)-2, respectively.

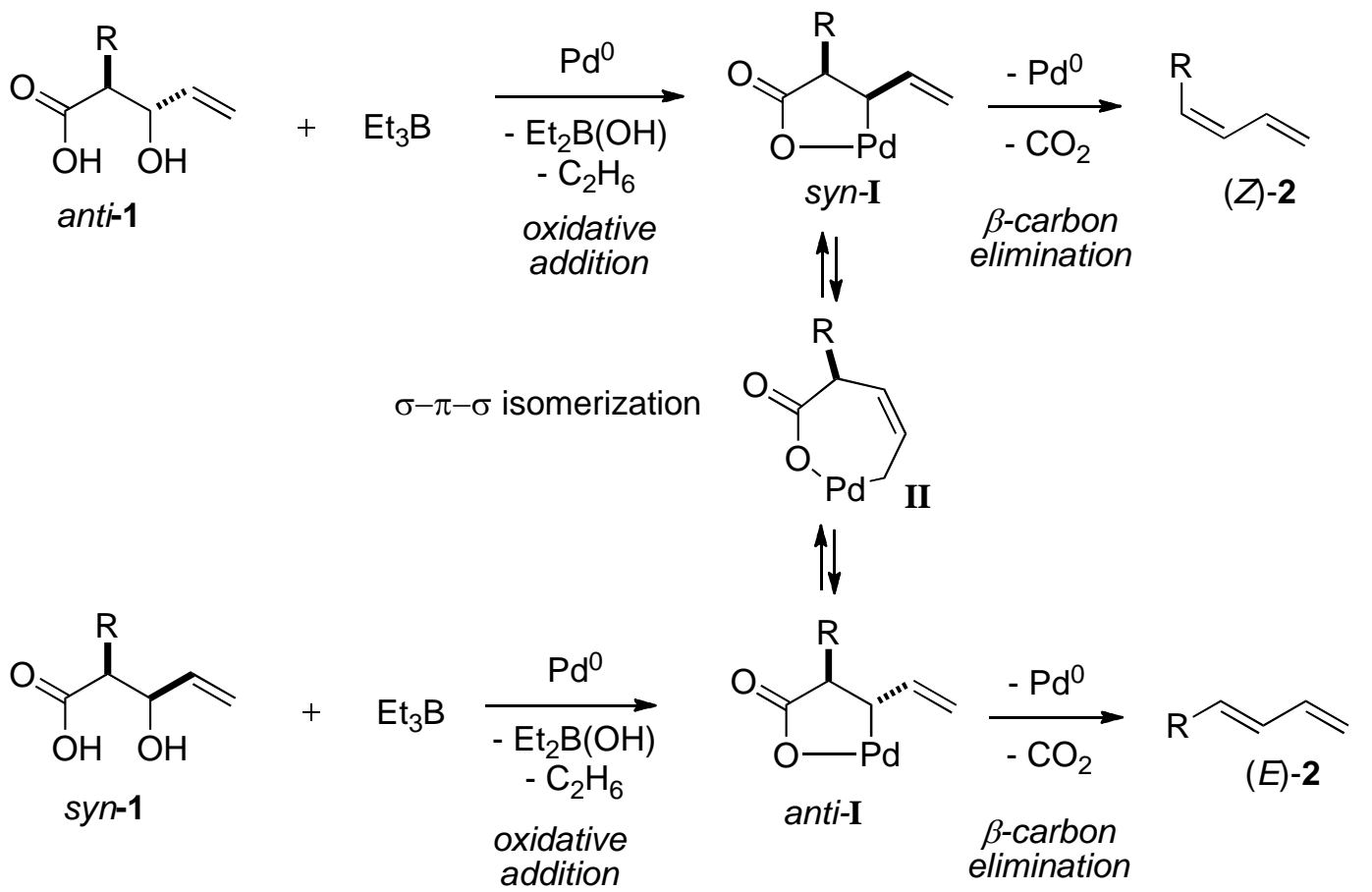

Scheme 3. Reaction Mechanism for Pd-Catalyzed Decarboxylative C-C Bond Cleavage 
As a result of the formation of $(2 E, 4 E)-\mathbf{2 b}$ as a major product along with (2E, $4 Z)$ and $(2 Z, 4 E)-2 \mathbf{b}$ from a mixture of syn-(E)-1b and anti-(E)-1b (runs 2, Table 1), a plausible mechanism for the C-C bond cleavage reaction of 2,5-disubstituted-3-hydroxy-4-pentenoic acids 1 might be illustrated in Scheme 4.
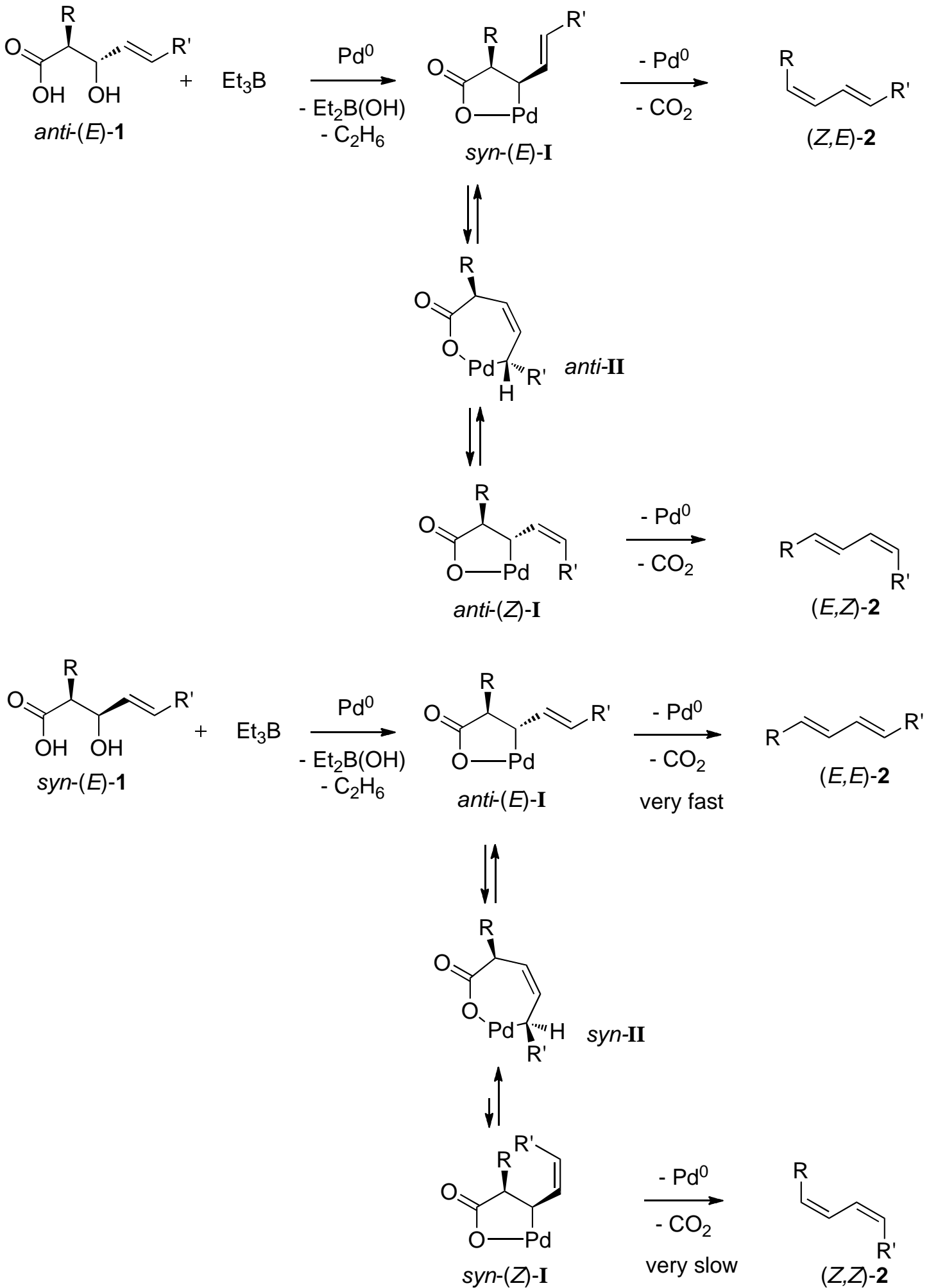

Scheme 4. C-C Bond Cleavage of 2,5-Disubstituted-3-hydroxy-4-pentenoic Acids 
It seems that anti-(E)-1b provides a mixture of $(Z, E)$ - and $(E, Z)-\mathbf{2 b}$ in modest yields being in equilibrium with syn-(E)-I and anti-(Z)-I via seven-membered palladacycle anti-II. On the contrary, formation of anti-(E)-I from syn-(E)-1b by oxidative addition of $\operatorname{Pd}(0)$ catalyst with $\mathrm{Et}_{3} \mathrm{~B}$ predominates over the formation of syn-(Z)-I by $\sigma-\pi-\sigma$ interconversion through syn-II, and causes the C-C bond cleavage reaction smoothly providing $(E, E)$-2b in excellent yield. Selective formation of $(Z, Z)$-2b through the unstable intermediate syn-(Z)-I is extremely improbable owing to the most unfavorable stereochemistry. In summary, we have shown that a combination of $\operatorname{Pd}(0)$ catalyst and $\mathrm{Et}_{3} \mathrm{~B}$ effectively activates 3-hydroxy-4-pentenoic acid to undergo $\beta$-decarboxylative $\mathrm{C}$-C bond cleavage reaction via $\beta$-vinyloxapalladacyclopentanone to form a conjugated diene with high stereoselectivity. The present methodology would be utilized for the convenient and stereodefined construction of conjugated dienes from readily available esters and $\alpha, \beta$-unsaturated aldehydes with great operational ease.

\section{ACKNOWLEDGEMENTS}

Financial support from the Ministry of Education, Culture, Sports, Science, and Technology, Japanese Government (Grant-in-Aid for Scientific Research (B) 21350055) is gratefully acknowledged. This work was partially supported by the Asahi Glass Foundation.

\section{REFERENCES AND NOTES}

1. E. Negishi, S. J. Holmes, J. M. Tour, J. A. Miller, F. E. Cederbaum, D. R. Swanson, and T. Takahashi, J. Am. Chem. Soc., 1989, 111, 3336; N. M. Kablaoui, and S. L. Buchwald, J. Am. Chem. Soc., 1995, 117, 6785; W. E. Crowe, and M. J. Rachita, J. Am. Chem. Soc., 1995, 117, 6787; M. Caellani, Synlett, 2003, 298; M. Kimura and Y. Tamaru, Topics in Current Chemistry, 2007, 279, 173; M. Jeganmohan and C.-H. Cheng, Chem. Eur. J., 2008, 14, 10876; M. Catellani, E. Motti, and N. D. Cá, Acc. Chem. Res., 2008, 41, 1512.

2. Y. Sato, M. Takimoto, K. Hayashi, T. Katsuhara, K. Takagi, and M. Mori, J. Am. Chem. Soc. 1994, 116, 9771; Y. Sato, N. Saito, and M. Mori, Tetrahedron 1998, 54, 1153; M. Kimura, A. Ezoe, K. Shibata, and Y. Tamaru, J. Am. Chem. Soc., 1998, 120, 4033; M. Kimura, H. Fujimatsu, A. Ezoe, K. Shibata, M. Shimizu, S. Matsumoto, and Y. Tamaru, Angew. Chem. Int. Ed., 1999, 38, 397; M. Kimura, S. Matsuo, K. Shibata, and Y. Tamaru, Angew. Chem. Int. Ed., 1999, 38, 3386; Y. Sato, M. Takimoto, and M. Mori, J. Am. Chem. Soc., 2000, 122, 1624; Y. Sato, R. Sawaki, and M. Mori, Organometallics, 2001, 20, 5510; Y. Sato, N. Saito, and M. Mori, J. Org. Chem., 2002, 67, 9310; R. Sawaki, Y. Sato, and M. Mori, Org. Lett., 2004, 6, 1131; M. Kimura, A. Ezoe, M. Mori, K. Iwata, 
and Y. Tamaru, J. Am. Chem. Soc., 2006, 128, 8559; S. Ogoshi, K. Tonomori, M. Oka, and H. Kurosawa, J. Am. Chem. Soc., 2006, 128, 7077; Y. Yang, S. F. Zhu, H. F. Duan, C. Y. Zhou, L. X. Wang, and Q. L. Zhou, J. Am. Chem. Soc., 2007, 129, 2248; H. Y. Cho, and J. P. Morken, J. Am. Chem. Soc., 2008, 130, 16140; N. Saito, T. Yamazaki, and Y. Sato, Tetrahedron Lett., 2008, 49, 5073; N. Saito, T. Yamazaki, and Y. Sato, Chem. Lett., 2009, 594.

3. M. Mori, M. Kimura, Y. Takahashi, and Y. Tamaru, Chem. Commun., 2006, 4303.

4. H. Harayama, K. Kuroki, S. Tanaka, M. Kimura, and Y. Tamaru, Angew. Chem. Int. Ed. Engl., 1997, 36, 2352; H. Harayama, M. Kimura, S. Tanaka, and Y. Tamaru, Tetrahedron Lett., 1998, 39, 8475.

5. M. Kimura, M. Mori, and Y. Tamaru, Chem. Commun., 2007, 4504.

6. B. M. Trost and J. M. Fortunak, J. Am. Chem. Soc., 1980, 102, 2841.

7. 3-Hydroxy-4-pentenoic acids $\mathbf{1}$ were easily prepared from lactones or esters with $\alpha, \beta$-unsaturated aldehydes by crossed-aldol reaction followed by hydrolysis in aqueous alkaline conditions.

8. Under similar conditions, no reaction proceeds in the presence of $\mathrm{Ph}_{3} \mathrm{~B}$, instead of $\mathrm{Et}_{3} \mathrm{~B}$.

9. Typical reaction procedure (run 1, Table 1): Into a $\mathrm{N}_{2}$ purged flask containing 3-hydroxy-4-pentenoic acid 1a (141 mg, $0.5 \mathrm{mmol}), \mathrm{Pd}\left(\mathrm{PPh}_{3}\right)_{4}(27.8 \mathrm{mg}, 0.025 \mathrm{mmol})$ purged with nitrogen were successively THF (2.5 mL) and triethylborane (1.8 mL, $1 \mathrm{M}$ hexane; Aldrich) were introduced successively via a syringe. The reaction mixture was stirred at $67^{\circ} \mathrm{C}$ for $1 \mathrm{~h}$, during which the reaction was monitored by means of TLC. After dilution with EtOAc $(30 \mathrm{~mL})$, the mixture was washed with sat. aq. $\mathrm{NaCl}(30 \mathrm{~mL})$. The organic layer was dried $\left(\mathrm{MgSO}_{4}\right)$ and the solvent was removed in vacuo. The residue was subjected to the column chromatography over silica gel (Wakogel C-300; eluent: hexane) and (1E,3E)-1,5-diphenylpenta-1,3-diene 2a (209 mg, 95\%) was obtained in 18:1 ratio. (1E, 3E)-1,5-Diphenylpenta-1,3-diene (2a): IR (neat) 3024 (m), 1596 (w), 1495 (m), 1452 (m), 988 (s), 741 (m), 694 (m) cm ${ }^{-1}$; ${ }^{1} \mathrm{H}$ NMR (400 MHz, CDCl , major isomer): $\delta 3.48$ (d, $J=7.0 \mathrm{~Hz}, 2 \mathrm{H}$ ), 5.96 (dt, $J=14.9,7.0 \mathrm{~Hz}, 1 \mathrm{H}$ ), 6.25 (dd, $J=14.9,10.5 \mathrm{~Hz}, 1$ H), 6.47 (d, $J=15.7 \mathrm{~Hz}, 1 \mathrm{H}), 6.77$ (dd, $J=15.7,10.5 \mathrm{~Hz}, 1 \mathrm{H}), 7.19$ - 7.41 (m, $10 \mathrm{H}) ;{ }^{13} \mathrm{C}$ NMR (400 MHz, $\mathrm{CDCl}_{3}$, major isomer): $\delta$ 39.2, 126.0, 126.1, 127.1, 128.3, 128.4, 128.5, 128.8, 130.8, 131.6, 133.5, 137.4, 140.0; ${ }^{1} \mathrm{H}$ NMR (400 MHz, $\mathrm{CDCl}_{3}$, minor isomer): $\delta 3.65$ (d, $J=7.6 \mathrm{~Hz}, 2 \mathrm{H}$ ), 5.69 (dt, $J=10.5,7.6 \mathrm{~Hz}, 1 \mathrm{H}), 6.25$ (t, $J=10.5 \mathrm{~Hz}, 1 \mathrm{H}), 6.61$ (d, $J=15.6 \mathrm{~Hz}, 1 \mathrm{H}), 6.77$ (dd, $J=$ 15.7, $10.5 \mathrm{~Hz}, 1 \mathrm{H}), 7.19-7.41$ (m, $10 \mathrm{H}$ ); ${ }^{13} \mathrm{C} \mathrm{NMR} \mathrm{(400} \mathrm{MHz,} \mathrm{CDCl}_{3}$, minor isomer): $\delta 34.2$, 126.0, 126.3, 127.4, 128.3, 128.4, 128.5, 129.5, 130.6, 131.6, 133.0, 137.4, 140.3; High-resolution MS, calcd for $\mathrm{C}_{17} \mathrm{H}_{16}$ : 220.3089. Found $\mathrm{m} / \mathrm{z}$ (relative intensity): 221.1271 (18), 220.1252 ( $\left.\mathrm{M}^{+}, 100\right)$, 219.1181 (3).

10. The original dihydrocoumarins by competing lactonization of $\mathbf{1 e}$ and $\mathbf{1 f}$ were produced in $12 \%$ and 20\% yields, respectively (runs 5 and 6 , Table 1 ). 